\title{
Criação, disseminação e Gestão do Conhecimento nas comunidades estratégicas
}

\author{
Augusto de Toledo Cruz Junior, M.Sc. \\ Escola Politécnica da Universidade de São Paulo \\ Departamento de Engenharia de Produção \\ seneng@uol.com.br
}

Marly Monteiro de Carvalho, Ph.D.

Escola Politécnica da Universidade de São Paulo

Departamento de Engenharia de Produção

marlymc@usp.br

Fernando José Barbin Laurindo, Ph.D.

Escola Politécnica da Universidade de São Paulo

Departamento de Engenharia de Produção

fjblau@usp.br

Marcelo Schneck de Paula Pessoa, Ph.D.

Escola Politécnica da Universidade de São Paulo

Departamento de Engenharia de Produção

mpessoa@usp.br

O desenvolvimento da Tecnologia da Informação viabiliza redes de informação que permitem a criação de uma grande variedade de negócios, com o objetivo de inovar as competências essenciais, e simultaneamente criar novos valores para seus clientes através de alianças estratégicas focadas na gestão do conhecimento dos envolvidos, denominadas comunidades estratégicas. O artigo analisa a criação, disseminação e gestão do conhecimento nas comunidades estratégicas já relatado através de estudos de casos, e explora por associação elementos teóricos que ainda não se encontram claros neste mecanismo, visando permitir a aplicação prática do modelo de comunidade. Para tanto, realiza a busca dos elementos faltantes nas teorias associadas ao conceito de espiralar o conhecimento e alcança resultados que descrevem o local onde a comunidade cria o conhecimento, como as ferramentas da TI são utilizadas, e quando são aplicadas, além de um framework completo com a dinâmica da comunidade estratégica.

Palavras-chave: comunidade estratégica; gestão do conhecimento; tecnologia da informação.

The development of Information Technology makes possible to build up information networks that also make possible to create new businesses, with the objective of innovating the core competences, and simultaneously create new values for customers. It is created strategic alliances centered in the knowledge management of the involved ones that are named strategic communities. The article analyzes the creation, dissemination and management of the knowledge in the strategic communities divulgated through studies of cases, and explores using association theoretical elements that are not clear its mechanism, aiming to allow the practical application of the community model. The research was done in the theories associates to the concept of spiral knowledge and reaches results that describe the place where the community creates the knowledge, how the TI tools are used, and when they are applied, beyond a complete framework with the dynamics of the strategic community.

Keywords: strategic community; knowledge management; information technology.

\section{Introdução}

Atualmente uma grande variedade de negócios utilizando a Internet e outras redes de informação tem aparecido em função do desenvolvimento das tecnologias da TI (tecnologia da informação). Esses negócios não se limitam a utilizar apenas os próprios recursos da empresa, como conhecimento, competência, pessoal, etc., mas também criam formas de colaboração envolvendo relacionamentos externos, incluindo clientes, com o objetivo de inovar as competências essenciais (core competences) das organizações, e simultaneamente criar novos valores para seus clientes

(PRAHALAD e HAMEL, 1990; DUHAN et al., 2001). 
Como pano de fundo desses negócios existem alianças estratégicas que atuam na gestão do conhecimento dos envolvidos. Kadama (2002) e Kodama (1999a; 1999b; 1999c; 2002) relatam aplicações práticas de um tipo específico dessas alianças, o qual denominam de comunidade estratégica, e que segundo Kadama (2002) pode ser entendida como um grupo versátil, composto de elementos de dentro e fora de uma organização, o qual através de novos produtos e novos serviços é capaz de realizar inovações. Em função da abrangência da colaboração neste tipo de comunidade, normalmente se integram por sistemas da TI que suportam o seu funcionamento.

O embasamento teórico dos relatos referentes à criação e a disseminação do conhecimento na comunidade estratégica se apóia no processo de espiralar o conhecimento (NONAKA e TAKEUCHI,1997; NONAKAe TOYAMA, 2003) para explicar a criação e amplificação do conhecimento. Quanto às ferramentas da TI que dão suporte ao processo de espiralar, são apresentadas quais são as utilizadas e as consideradas mais apropriadas. No entanto, os relatos não esclarecem detalhes tais como:

a) se a tipologia dessa comunidade é tipicamente de conhecimento, ou não;

b) o local da criação do conhecimento para em seguida ser espiralado;

c) a interação das ferramentas da TI com as fases do processo de espiralar.

A falta desses detalhes acaba inviabilizando a replicação desse modelo de comunidade em ambientes semelhantes, os quais se tornam cada vez mais presentes nos nossos negócios. Portanto, justifica ser estudado para tornar o modelo aplicável.

Em função do exposto, este artigo tem como objetivo contribuir na exploração dos detalhes não totalmente esclarecidos, mantendo-se fiel ao embasamento teórico central do processo de espiralar o conhecimento, ou seja, é realizado um recorte na literatura analisando-se apenas os elementos associados a esse processo.

O artigo também pretende contribuir com a proposta de um framework, mais completo que o apresentado por Kadama (2002), o qual sintetize a dinâmica da criação e disseminação do conhecimento da comunidade estratégica, incluindo as explorações realizadas neste artigo.

Para executar o proposto, a seção 1 trata dos levantamentos dos elementos que atuam na gestão do conhecimento, associados ao recorte proposto. Inicia com os conceitos das organizações baseadas em trabalho e em conhecimento (LAWLER, 1994 apud LINDGREN et al., 2003). Em seguida, é revisto mais detalhadamente o processo de espiralar o conhecimento (NONAKA e TAKEUCHI,1997) através do processo do modelo denominado SECI (Socialização; Externalização;
Combinação; Internalização) (NONAKA e TOYAMA, 2003), para compreender melhor o embasamento central utilizado para a comunidade estratégica. Ainda é explorado o conceito referente ao lugar onde o conhecimento é criado, através do conceito do Ba (NONAKA e TOYAMA, 2003), visando esclarecer detalhes quanto ao local da criação do conhecimento, para em seguida ser espiralado. Esta seção é finalizada com a exploração da interação das ferramentas da TI com as fases do processo de espiralar (CARVALHO e FERREIRA, 2001).

Na seção 2 são sintetizadas as características da comunidade estratégica relatadas por Kodama (1999a; 1999b; 1999c; 2002) e Kadama (2002), além do framework apresentado por Kadama (2002), com a função de permitir que na seção 3 se realize a discussão com os elementos explorados na seção 1, e finalizar com proposição do framework mais completo.

A seção 4 apresenta as conclusões e as pendências a serem resolvidas em uma agenda futura.

\section{A disseminação do conhecimento}

\subsection{As organizações baseadas em trabalho e em conhecimento}

A extensa literatura descreve tipologias de formas organizações, que podem ser divididas em organização baseada em trabalho e organização baseada em conhecimento (LAWLER, 1994 apud LINDGREN et al., 2003). Uma organização baseada no trabalho pode ser descrita como um conjunto de máquinas que coordena bem um repertório fixo de rotinas, onde o quadro que se vê é a ordem, a previsibilidade e a hierarquia (LINDGREN et al., 2003).

Lindgren et al. (2003, p. 21, grifo do autor) afirma que Drucker (1988; 1993) apud Lindgren et al. (2003)

"cunhou a frase 'trabalho de conhecimento' de maneira a descrever o aumento de importância do conhecimento na sociedade emergente pós-industrial". Esse trabalho de conhecimento desafia a rotina e requer o uso da criatividade para produzir conhecimento (BLACKLER, 1995 apud LINDGREN et al., 2003). Conforme Lindgren et al. (2003), o conceito de trabalho de conhecimento é estendido para organizações baseadas em conhecimento, as quais praticam o trabalho de conhecimento e distinguem-se por conviverem num ambiente de mudanças condições, sob exigências inesperadas e um aprendizado contínuo. Nelas há uma necessidade constante de inovação que requer o uso de sistemas de competências baseados numa melhor interpretação das competências que são desenvolvidas sobre os próprios interesses dos indivíduos no trabalho e que possam ser utilizados pela organização. 
Apesar de uma organização baseada em conhecimento se contrapor à rigidez da organização baseada no trabalho, não significa que não possam conviver e que sejam mutuamente exclusivas. "Normalmente, ambas as formas podem ser encontradas em áreas diferentes, departamentos, ou níveis dentro da mesma organização" (NONAKA, 1994 apud LINDGREN et al., 2003, p. 21).

As comunidades estratégicas podem ser entendidas como organizações que atuam principalmente baseadas em conhecimento, mas também não deixam de atuar como organizações baseadas em trabalho. Desta maneira, a seguir, são revistas as teorias que podem auxiliar no entendimento da atuação das comunidades estratégicas como organização baseada em conhecimento.

\subsection{O processo de espiralar o conhecimento}

Conhecimento explícito é aquele que está codificado, pode ser encontrado em documentos, projetos e materializado no próprio produto, enquanto que o conhecimento tácito é aquele que reside na mente das pessoas, é ligado à experiência, difícil de ser compartilhado e depende da história de vida de cada um, de seus valores e modelos mentais (NONAKA e TAKEUCHI, 1997). Apesar de distintos, o conhecimento tácito e o explícito não são entidades separadas e sim mutuamente complementares que interagem entre si e realizam trocas nas atividades criativas dos indivíduos (NONAKA e TAKEUCHI,1997).

Para entender como é possível sintetizar o ambiente e os recursos envolvidos, Nonaka e Toyama (2003) visitam a Teoria da Estruturação de Giddens (1984) apud Nonaka e Toyama (2003), a qual afirma que o ser humano age de acordo com a imagem que faz da realidade e estuda a maneira que o sistema social é produzido e reproduzido na interação social. Se o ambiente influencia o agente, este por sua vez recria continuamente seu ambiente pela interação social, ou seja, o conhecimento é criado pela interação entre o agente humano e estruturas sociais. Também argumenta que nossas ações são conduzidas por dois principais níveis de consciência: a discursiva e a prática. A primeira assemelha-se aos conhecimentos explícitos porque nos dá a racionalidade para as ações conscientes e a segunda refere-se ao nível de nossas vidas que nós não pensamos ou teorizamos, ou seja, pode-se dizer que os conhecimentos tácitos são produzidos pela consciência prática. A criação do conhecimento começa com a socialização, que ocorre quando certa pessoa compartilha conhecimento tácito diretamente com outra pessoa pela interação social. A externalização ocorre quando a pessoa é capaz de expressar os fundamentos do conhecimento tácito por conceitos, imagens e escrevendo documentos. As pessoas são capazes de combinar componentes isolados de conhecimentos explícitos. Os conhecimentos explícitos coletados internamente e externamente servem para a constituição de um novo, o qual é disseminado entre os membros da organização. Pode-se observar a internalização quando o conhecimento explícito é compartilhado em toda organização, e os empregados começam a internalizá-lo, utilizando-o para ampliar, estender e reformular seus próprios conhecimentos tácitos.

Em função da argumentação da Teoria da Estruturação de que o conhecimento é criado por meio da interação entre o conhecimento tácito e o conhecimento explícito, Nonaka e Takeuchi (1997) propõem quatro modos diferentes de conversão do conhecimento:

a) socialização: de conhecimento tácito para conhecimento tácito;

b) externalização: de conhecimento tácito para conhecimento explícito;

c) combinação: de conhecimento explícito para conhecimento explícito;

d) internalização: de conhecimento explícito para conhecimento tácito.

Além disso, Nonaka e Takeuchi (1997) ilustram o processo de funcionamento dos quatros modos de conversão do conhecimento e suas interações com o ambiente, através do modelo denominado SECI (Socialização; Externalização; Combinação; Internalização), o qual pode ser visto na Figura 1.

A dinâmica do processo do modelo SECI ocorre formando uma espiral de criação, e não um círculo (NONAKA e TOYAMA, 2003), na qual a interação entre o conhecimento tácito e o explícito é amplificada pelos quatros modos de conversão do conhecimento do processo. A espiral torna-se ampla em escala e move-se então para níveis ontológicos e pode disparar uma nova espiral de criação de conhecimento expandindo horizontalmente e verticalmente de acordo como ela se move pelas comunidades de interação que transcende a seção, departamento, divisão e mesmo limites da organização, ou seja, pode haver interação de entre diferentes organizações (NONAKA e TOYAMA, 2003).

\subsection{Ba como o local de criação do conhecimento para o processo de espiralar}

Para o processo de criação do conhecimento é necessário um contexto específico em termos de tempo, espaço e relacionamento com os outros. O conhecimento não pode ser criado no vácuo, e precisa de um local onde são dados significados à informação pela interpretação para tornar-se conhecimento.

O conceito do ba, proposto originalmente pelo filósofo japonês Kitaro Nishida (NISHIDA, 1921; 1970 apud NONAKA e TOYAMA, 2003), e que grosso modo significa lugar, é definido por Nonaka e Toyama (2003) como um contexto compartilhado em movimento, onde o conheci- 
mento é compartilhado, criado e utilizado (NONAKA e TOYAMA, 2003). Ba fornece a energia, qualidade e local para executar conversões de conhecimentos individuais e para mover ao longo da espiral do conhecimento. Em outras palavras, ba é um espaço e tempo fenomenológico onde um grupo de conhecimentos emerge. Novos conhecimentos são extraídos de conhecimentos existentes pela mudança do significado do contexto.

Ba pode surgir em indivíduos, grupo de trabalho, equipe de projeto, reuniões temporárias, espaço virtual com grupo de e-mails e contato direto com os clientes, etc. Ba é um local existencial onde os participantes compartilham seus contextos e criam novos significados pelas interações. Participantes do ba trazem seu próprio contexto, mas pela interação com os outros e o ambiente, o contexto do ba, os participantes e o ambiente mudam conforme ilustrado na Figura 2.

Embora o conceito de ba seja similar ao conceito de comunidade de prática, a diferença reside no fato de que enquanto a comunidade de prática é estável, e para se tornar um participante pleno leva tempo para aprender sobre a comunidade, no ba os participantes vêm e vão. Pela definição, ba envolve várias contradições. Ba requer múltiplos contextos, e ainda, um compartilhamento dos mesmos para existir. Um bom ba precisa de participantes com múltiplos pontos de vista, assim podem trazer vários contextos para serem compartilhados. Ainda, o ba é um local aberto onde participantes com seus próprios contextos podem vir e ir, contanto que ba como contexto compartilhado possa continuamente ser envolvido. Para um ba criar e manter energia, o limite do ba deveria ser mantido permeável, de forma a proteger o ba de influências externas e levar contextos necessários ao mesmo tempo. Ba leva também participantes a terem pontos de vista internos e externos, e ao mesmo tempo fornece um contexto compartilhado em movimento. Uma maneira de sintetizar o conhecimento no ba é ter diálogos dialéticos entre os participantes que trazem vários pontos de vista baseados em várias experiências.

O ba não está limitado a uma simples organização, mas pode ser criado cruzando os limites organizacionais. $\mathrm{Ba}$ pode ser construído como um acordo com o fornecedor, uma aliança com o competidor, ou uma relação de interação com os clientes, universidades, comunidade local ou governo, como mostra a Figura 3. Os membros da organização transcendem os limites participando de um ba, e quando o ba em que participam é conectado a outro ba, transcendem muito além destes limites.

Assim o ba dá a empresa capacidade para sintetizar. Criação de conhecimento é um processo humano dinâmico e gerente e trabalhadores crescem a cada processo. No ba os gerentes tornam-se líderes e crescem as suas capacidades para sintetizar vários bas através da sua experiência de participação no ba.

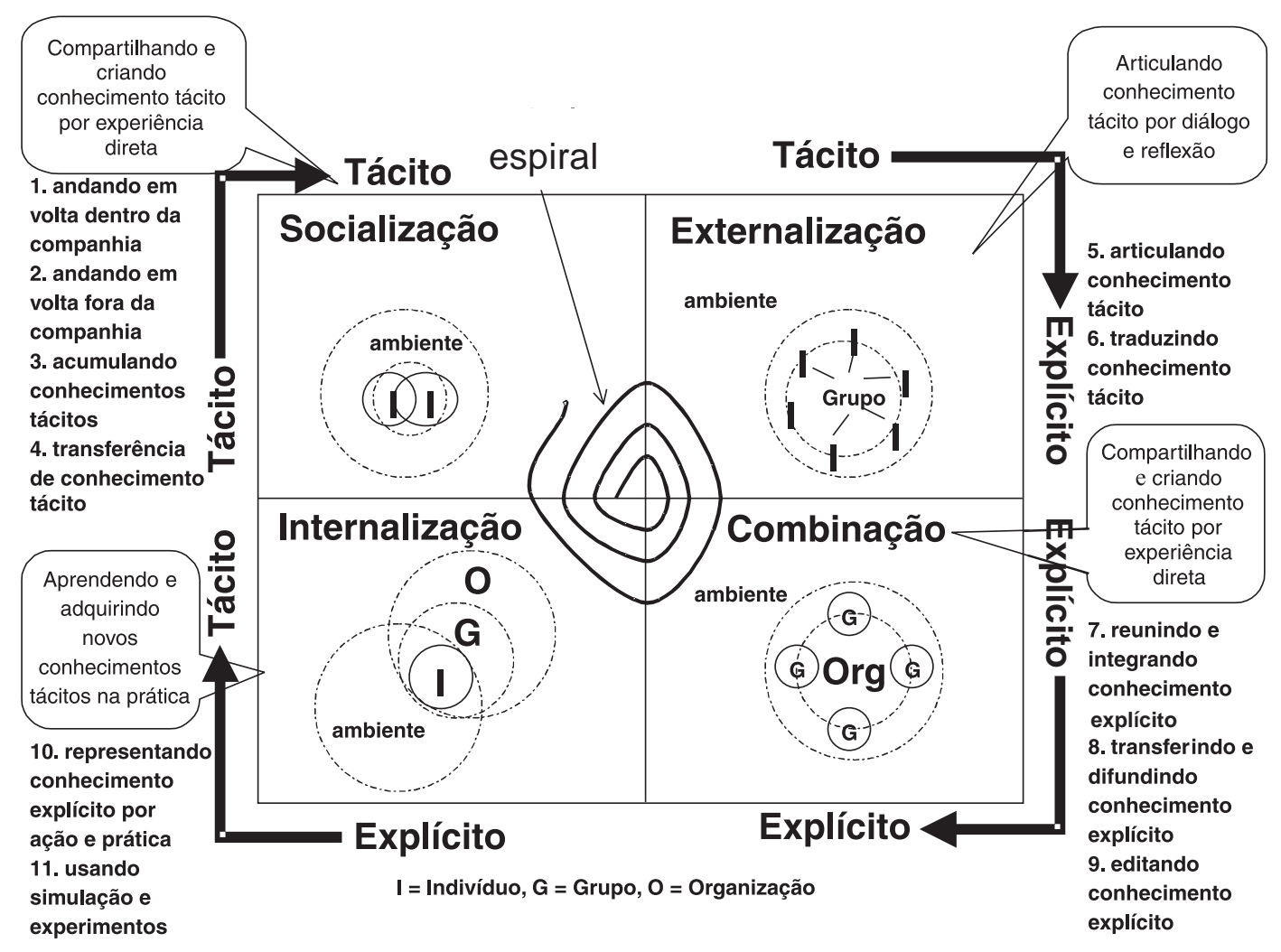

Fonte: adaptado de Nonaka e Toyama (2003, p.5) 


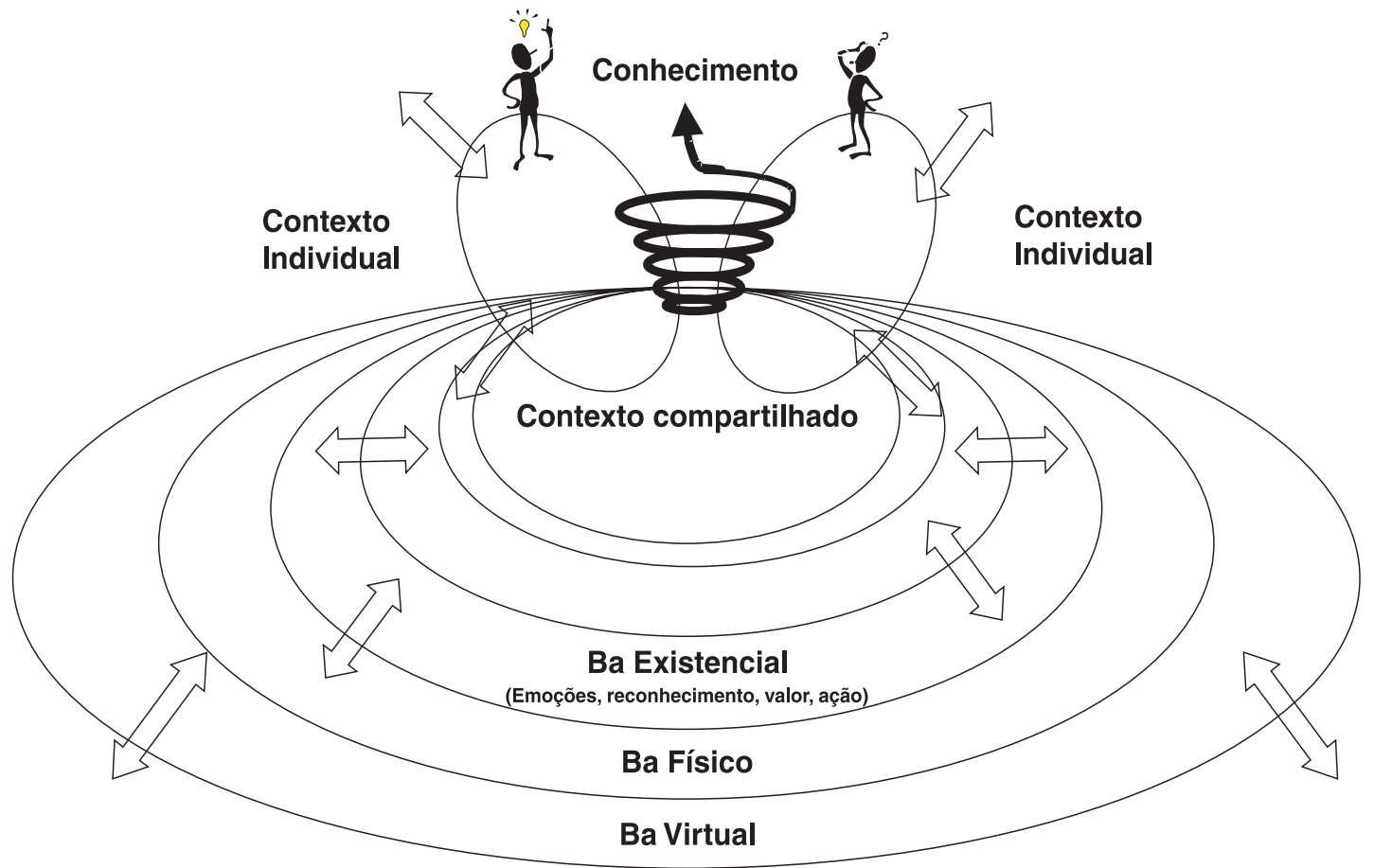

Fonte: Nonaka e Toyama (2003, p.7)

Ba

Figura 2 - Representação conceitual do ba

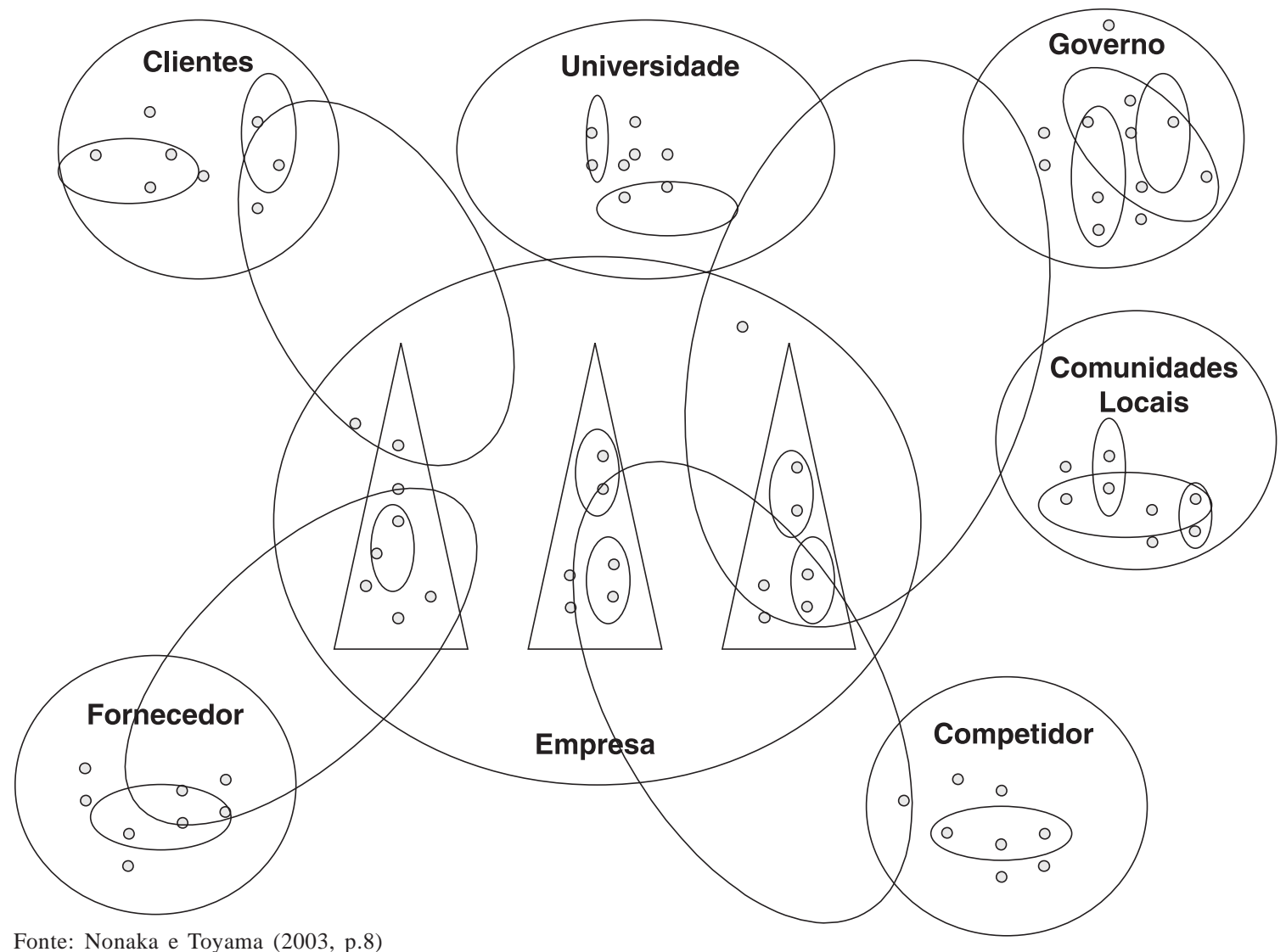

Figura 3 - Organização como configuração orgânica do ba 


\subsection{A TI como suporte nos modos de conversão do conhecimento}

Utilizando os modos de conversão do conhecimento proposto por Nonaka e Takeuchi (1997) e Carvalho e Ferreira (2001) propõem a perspectiva de suporte da TI conforme as características de cada tipo de software. No quadro da Figura 4 são apresentadas as aplicações dos softwares em cada quadrante do modo de conversão e as características sintéticas dos softwares.

\section{As comunidades estratégicas}

\subsection{Valores comuns na comunidade estratégica}

De acordo com Kadama (2002), um ponto importante na criação da comunidade estratégica é o estabelecimento de uma plataforma de valores harmonizados entre as várias entidades que participam da comunidade. Também Hesselbein et al. (1998) afirma que um dos pré-requisitos para a formação da comunidade estratégica é que todos os participantes possuam os mesmos valores. Desta maneira, a criação da comunidade estratégica depende da existência desses valores comuns, os quais são apresentados resumidamente a seguir.

A comunidade estratégica não é apenas uma única comunidade, mas em geral é a reunião de três tipos de comunidades, conforme ilustrado na Figura 5, e que apresentam as seguintes características (KODAMA, 1999a):

a) tipo 1: são comunidades existentes apenas dentro da organização, realizando tarefas diárias e rotineiras, compartilhando informação e conhecimento para o desenvolvimento da estratégia e tomando decisões do nível superior ao nível médio, e em seguida aos outros níveis, ou das matrizes para as filiais e escritórios de vendas;

b) tipo 2: são comunidades existentes por agrupamento com parceiros externos à organização, compartilhando conhecimento e informação, criando negócios, e realizando todo trabalho externo para a estratégia estabelecida;

c) tipo 3: são comunidades existentes entre a organização e os seus consumidores através de canais diretos e estratégias novas de marketing (projeto de um novo produto, desenvolvimento de serviços

\begin{tabular}{|c|c|c|}
\hline & PARA TÁCITO & PARA EXPLÍCITO \\
\hline \multirow{4}{*}{ DE TÁCITO } & Socialização & Externalização \\
\hline & \multirow{3}{*}{$\begin{array}{l}\text { Mapas de conhecimento } \Rightarrow \text { softwares } \\
\text { que funcionam como páginas } \\
\text { amarelas que organizam uma lista de } \\
\text { quem sabe o que }\end{array}$} & $\begin{array}{l}\text { Groupware } \Rightarrow \text { software projetado para auxiliar o trabalho de grupo de } \\
\text { pessoas, geralmente distantes fisicamente, mas que trabalham em } \\
\text { conjunto }\end{array}$ \\
\hline & & $\begin{array}{l}\text { Workflow } \Rightarrow \text { sistema informatizado é codificado o fluxo do processo, } \\
\text { mostrando as etapas corretas para a execução do mesmo e } \\
\text { acompanhamento de todas as atividades }\end{array}$ \\
\hline & & $\begin{array}{l}\text { Sistemas de bases inteligentes de conhecimento } \Rightarrow \text { conjunto de } \\
\text { ferramentas utilizadas para manipular grande massa de dados } \\
\text { estruturados armazenados em banco de dados, em busca de } \\
\text { informações essenciais para o negócio, usados para capturar uma } \\
\text { parcela do conhecimento de alguns para ser formatado e } \\
\text { compartilhado entre outros }\end{array}$ \\
\hline \multirow{3}{*}{ DE EXPLÍCITO } & Internalização & Combinação \\
\hline & \multirow{2}{*}{$\begin{array}{l}\text { Ferramentas de apoio à inovação } \Rightarrow \\
\text { softwares que contribuem para a } \\
\text { geração de conhecimento na fase de } \\
\text { concepção, estimulando a geração de } \\
\text { idéias }\end{array}$} & $\begin{array}{l}\text { Intranet } \Rightarrow \text { ferramentas baseadas na tecnologia da internet para } \\
\text { disponibilizar informações na rede interna da empresa }\end{array}$ \\
\hline & & $\begin{array}{l}\text { GED } \Rightarrow \text { Gerenciamento Eletrônico de Documentos, que são } \\
\text { repositórios de documentos que permitem uma recuperação mais } \\
\text { eficiente, melhor segurança e controle da versão de documentos, } \\
\text { funcionando como armazéns do conhecimento explícito }\end{array}$ \\
\hline
\end{tabular}

Fonte: adaptado de Carvalho e Ferreira (2001) 
que refletem as necessidades e reivindicações de clientes específicos, etc.). Esses consumidores envolvem desde grandes clientes até usuários gerais.

Kodama (1999a) sugere que a estratégia de gestão da comunidade é influenciada por dois fatores essenciais. O primeiro é o compartilhamento, criação, e desenvolvimento criativo de diversos recursos que podem ser informações, conhecimento e competências da comunidade. Isto se aplica tanto para as competências possuídas pelos indivíduos, como para as competências da comunidade toda.

O segundo fator essencial é a liderança para inovação exercida por líderes da comunidade, os quais, dependendo do trabalho que executem, podem estar na alta gerência das organizações, ou no nível médio. O que ções multimídias (KODAMA, 1999b; 1999c), procurando proporcionar a colaboração de alta qualidade necessária para a decisão dos líderes da comunidade, e para as interações entre os participantes, sistema chamado neste artigo de rede da comunidade.

Esta rede compreende a comunicação individual baseada em texto, por correio eletrônico e softwares de grupos de trabalho, de um nível que permite comunicação interativa fundindo os elementos imagem, voz e texto. Usa basicamente tecnologia da Internet e ISDN (Integrated Services Digital Network). Como aplicações são utilizadas tanto modelos interativos em tempo real, como sistemas de armazenamento, ou modelos em tempo não-real ilustrados no quadro da Figura 6.

Os modelos interativos em tempo real permitem a troca simultânea de informações de diferentes localidades.

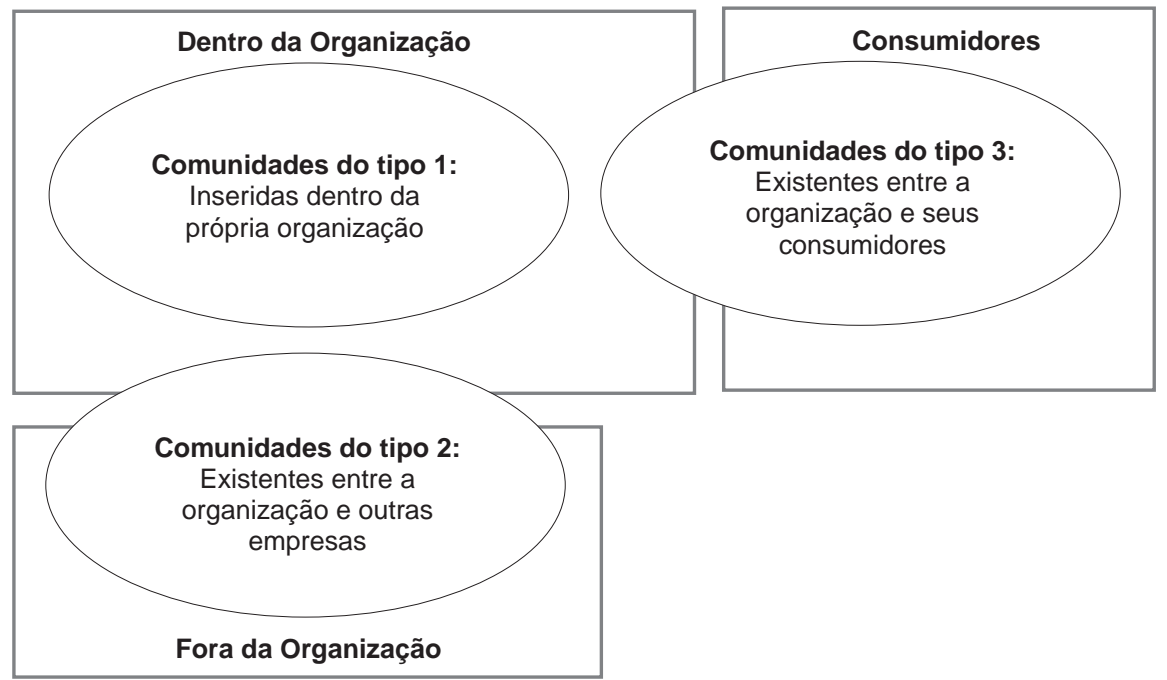

Fonte: adaptado de Kodama (1999a, p.141)

Figura 5 - Tipos de comunidades e seus relacionamentos

importa é que demonstrem liderança para inovação. Mesmo uma organização que tenha o melhor das competências da comunidade, sozinha não garante o sucesso (KODAMA, 1999a), ou seja, é necessário que essas competências sejam aproveitadas pela comunidade sob o comando destes líderes, promovendo a ressonância entre os membros para obtenção do objetivo comum.

\subsection{O suporte da TI no funcionamento das comunidades estratégicas}

Com a rápida inovação tecnológica nas redes multimídias digitais, agora é possível para as comunidades desenvolverem negócios fazendo uso intensivo da TI. Especificamente são utilizadas ferramentas como sistemas de rede de informações baseados em aplica-
Os sistemas típicos são os de vídeo conferência, terminais de vídeo como, por exemplo, telefones com vídeo, os quais são mais pessoais e fáceis de usar. Estes sistemas são interativos com imagens e vozes, mas também permitem o compartilhamento de informações com texto, sobrepondo com vantagens o correio eletrônico e softwares de trabalho em grupo, pois possibilitam a fácil comunicação dos pensamentos e intenções, permitindo um debate rico e de decisão rápida (KODAMA, 1999b; 1999c).

Os modelos de armazenamento permitem guardar as competências da comunidade tais como informações, conhecimento e especialidades, as quais não são de tempo real por natureza, situando-se em sistemas de armazenamento nos quais se pode buscar sob demanda. Sistemas típicos podem ser vídeos sob demanda que 


\begin{tabular}{|c|c|c|c|}
\hline & \multirow{2}{*}{ Voz } & \multirow{2}{*}{ Dados } & Vídeo, Voz e Dados \\
\hline & & & $\begin{array}{l}\text { Ferramentas do ambiente da rede } \\
\text { da comunidade }\end{array}$ \\
\hline Modelo de tempo real & Telefone & Fax & $\begin{array}{l}\text { - Vídeo conferência } \\
\text { - Telefone com vídeo }\end{array}$ \\
\hline $\begin{array}{l}\text { Modelo de tempo } \\
\text { não-real (sistema de } \\
\text { armazenamento) }\end{array}$ & $\begin{array}{l}\text { Correio de voz (voice } \\
\text { mail) }\end{array}$ & $\begin{array}{l}\text { Correio eletrônico (e-mail) } \\
\text { Softwares de trabalho em grupo } \\
\text { (groupware) }\end{array}$ & $\begin{array}{l}\text { Vídeo sob demanda (VDO - } \\
\text { vídeo-on-demand) }\end{array}$ \\
\hline
\end{tabular}

Fonte: adaptado de Kodama (1999b, p.189)

Figura 6 - Conceito das ferramentas de TI utilizadas pela rede da comunidade

permitem o acesso e busca em bancos de dados de imagens, e também correio de voz e informações com texto, utilizando como meio terminais de vídeo de equipamentos tais como sistemas de vídeo conferência e telefones com vídeo (KODAMA, 1999b; 1999c).

De acordo com os resultados de pesquisa apresentada em Kodama (1999a; 1999c), constatou-se que as ferramentas utilizadas na rede da comunidade se posicionam melhor para suporte na gestão estratégica do que outras ferramentas amplamente utilizadas, conforme ilustrado na Figura 5.

\subsection{A criação e disseminação do conhecimento na comunidade estratégica}

De acordo com o modelo apresentado na Figura 6, a comunidade estratégica se apóia numa liderança inovadora e na formação de uma plataforma de ressonância de estratégias comuns, e cria valor para seus consumidores, decorrente do relacionamento interativo entre o processo de espiralar o conhecimento da comunidade, em conjunto com o processo de avanço da competência da comunidade.

Kadama (2002) sugere que a inovação do conhecimento da comunidade ocorre por meio do desenvolvimento de um "processo de 'Compartilhamento para a Inspiração para a Criação para a Acumulação’ que espirala” (KADAMA, 2002, p.290, grifo do autor) o conhecimento da comunidade. Segundo Nonaka e Takeuchi (1997) e Nonaka e Toyama (2003), esse processo ocorre devido ao engajamento dos seus membros no diálogo e na colaboração. Como resultado tem-se o desenvolvimento e venda de produtos e serviços que os consumidores necessitam e repetidamente têm a sua qualidade melhorada, o que também resulta na melhoria da qualidade do conhecimento da comunidade
(KADAMA, 2002). Enquanto isso, o processo de avanço da competência corresponde ao avanço das competências essenciais da comunidade, as quais atingem um alto grau de sofisticação.

Conforme Kadama (2002), as competências da comunidade avançam em três modos (ver Figura 7):

a) compartilhamento: a competência da comunidade troca conhecimento sobre as várias alternativas e o processo de espiralar se encontra na fase inicial conceituando o produto ou serviço;

b) criação: a competência da comunidade estabelece alto padrões de qualidade para o produto ou serviço e o processo de espiralar se encontra na fase de crescimento promovendo uma estratégia integrada;

c) renovação: a competência da comunidade cria o novo produto ou serviço e o processo de espiralar se encontra na fase de desenvolvimento iniciando o fornecimento do produto ou serviço.

Para que a inovação ocorra através da gestão da comunidade estratégica, são relevantes pelo menos dois pontos (KADAMA, 2002):

1. o líder da comunidade deve compreender a situação em termos de cinco elementos: ambiente, tecnologia, mercado, consumidor e competição;

2. o líder deve estar capacitado para descobrir ou recrutar novos líderes, tanto dentro como fora da sua organização. Com essa capacitação será possível formar a plataforma de valores harmonizados trabalhando com os novos líderes, possibilitando a criação de comunidades estratégicas organizadas e a realização de inovação. 


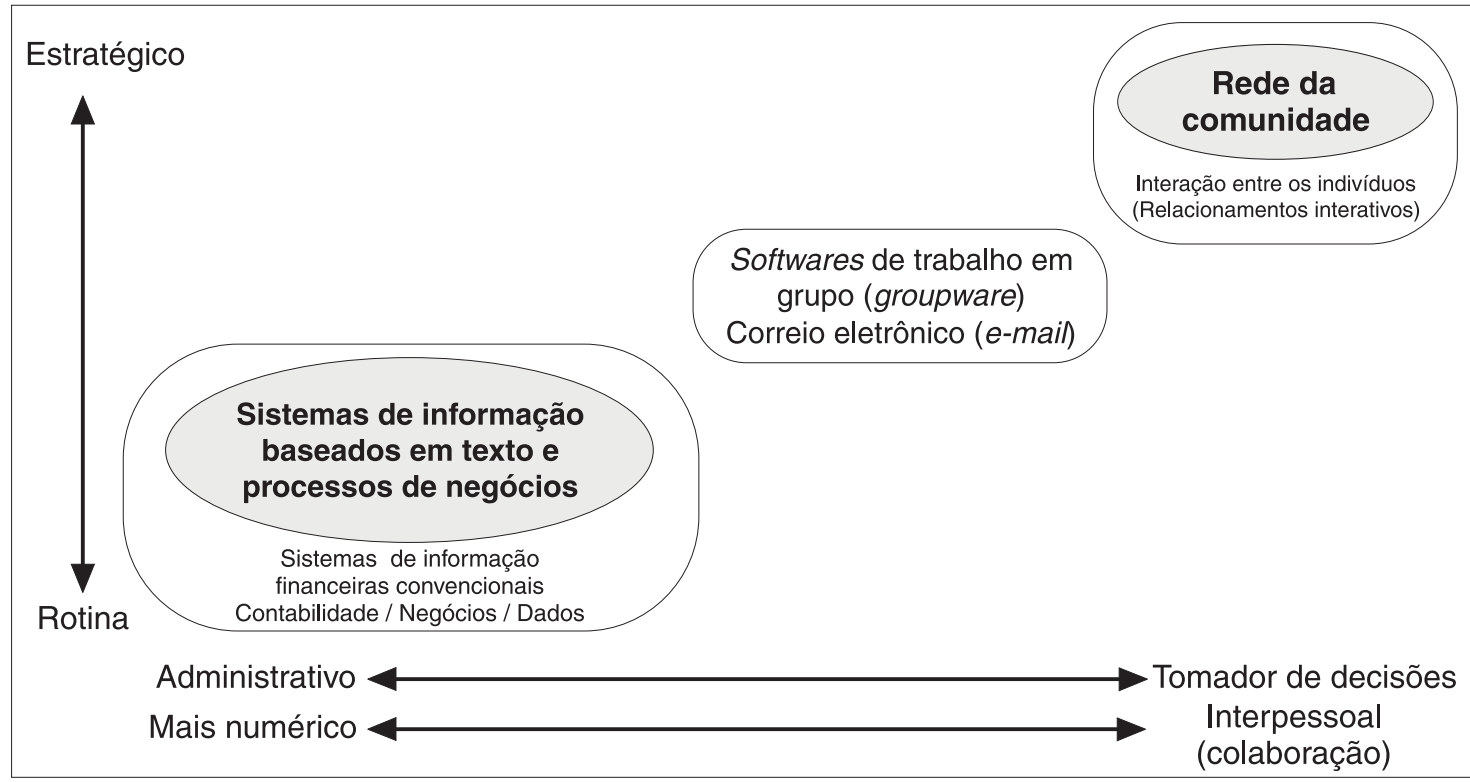

Fonte: Kodama (1999a, p. 144)

Figura 7 - Posicionamento das ferramentas da rede da comunidade em relação a outras ferramentas

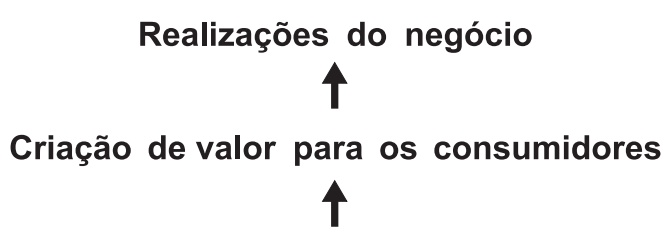

\section{Criação e inovação organizadas da comunidade estratégica}
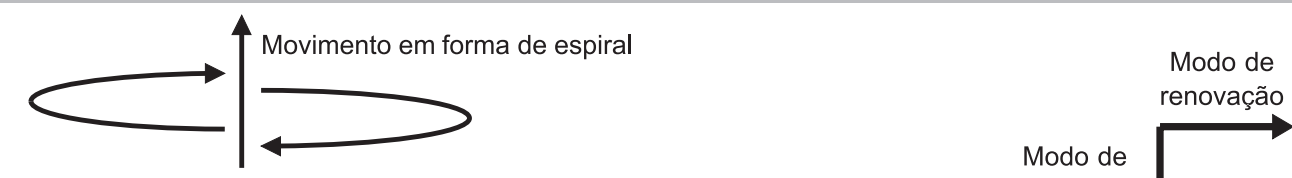

enovação

Modo de criação

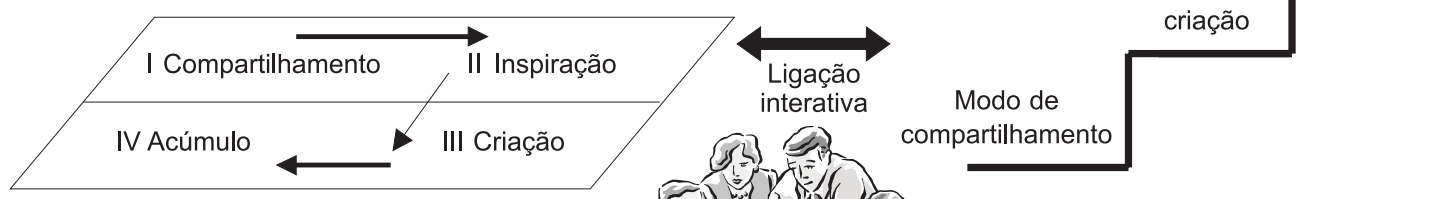

Inovação no conhecimento da comunidade

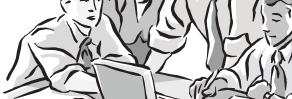

Avanço das competências da comunidade

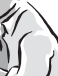

Formação da plataforma de ressonância do senso de valor dentro de uma estratégia comum

\section{$\uparrow$ \\ Base para criação da comunidade}

Liderança inovadora dos líderes da comunidade

Fonte: Kadama (2002, p. 301)

Figura 8 - Criação e inovação organizada da comunidade estratégica 


\subsection{Algumas diferenças da comunidade estratégica em relação a outras estruturas organizacionais}

De maneira a não confundir a comunidade estratégica com outras estruturas organizacionais como, por exemplo, as estruturas organizacionais por projeto e comunidade de prática, Kodama (2002) e Kadama (2002) esclarecem que as estruturas por projeto são bem formais e se baseiam em planos estratégicos muito bem definidos que são geridos pela alta direção, onde etapas e objetivos são bem detalhados. Para executar esses planos são apropriadas pessoas da própria organização, e algumas vezes de fora dela, por um período definido, seguindo uma estratégia deliberada até que o projeto tenha sido completado. É uma das mais efetivas estruturas organizacionais. No entanto, Bresnen et al. (2003) apud Donk e Riezebos (2004) afirmam que estudos empíricos mostram que as organizações por projeto têm dificuldade em aprender através dos projetos, provavelmente porque o conhecimento disponível não é fácil de ser adquirido. Além disso, não há literatura ou prática de gestão que indique um método apropriado que ensine a adquirir esse conhecimento neste tipo de estrutura. As ferramentas aplicáveis da TI normalmente visam mais o monitoramento do cumprimento da estratégia adotada, do que a promoção de colaboração entre os participantes.

Contrariamente a estrutura formal por projeto, tem-se a comunidade de prática que age informalmente através de uma auto-organização com membros voluntários e virtuais da organização a que pertence. Sua estrutura organizacional tem como objetivo promover melhorias no processo dos negócios das operações diárias. Costuma ser difícil obter recursos para a sua sustentação, e em geral, suas atividades não são distintas das atividades da organização, e em muitos casos não são autorizadas, permanecendo enquanto o interesse dos membros continua. Em função destas características, na comunidade de prática não há uma necessidade de ferramentas específicas da TI.

Kodama (2002) e Kadama (2002) sugerem que a comunidade estratégica é aplicável em casos onde as previsões são difíceis e os responsáveis pela sua gestão são surpreendidos por inúmeros eventos para os quais ainda não há estratégias de solução validadas. Nela se aplica o método de tentativa e erro, onde a estratégia surge das ações que são tomadas, e não há prazo definido para terminar, ou seja, a comunidade é mantida enquanto for necessária. Alternativamente a estrutura por projetos, o centro da estratégia na comunidade estratégica é ocupada pela gerência intermediária, a qual procura formar grupos virtuais tanto dentro como fora das organizações que fazem parte da comunidade, incluindo clientes, para gerar novas demandas e criar novos mercados. Para tanto, é fundamental o apoio de ferramentas de TI que promovam ampla colaboração entre seus membros.

\section{Discussão}

\subsection{Quanto à tipologia da comunidade estratégica em relação ao conhecimento}

Pelas características da comunidade estratégica, descritas na Introdução, ela atua como organização baseada em conhecimento, pois pratica o trabalho de conhecimento (LINDGREN et al., 2003) e vive em um ambiente de mudanças de condições, sob exigências inesperadas e um aprendizado contínuo, que são as características de uma organização baseada em conhecimento. No entanto, ao menos as comunidades dentro e fora da organização (comunidades dos tipos 1 e 2 da seção 2.1) convivem com organizações baseadas no trabalho pois se relacionam respectivamente com outras empresas e consumidores como grandes clientes (também empresas). Desta maneira confirma a observação de que "normalmente, ambas as formas podem ser encontradas em áreas diferentes, departamentos, ou níveis dentro da mesma organização" (NONAKA, 1994 apudLINDGREN et al., 2003, p. 21).

\subsection{Quanto ao local da criação do conhecimento para em seguida ser espiralado}

Conforme exposto na seção 2.1, e também ilustrado na Figura 4, a criação de uma comunidade estratégica ocorre da reunião de comunidades que podem ser associadas ao conceito da sintetização de bas descrito na seção 1.3. Assim sendo, uma outra maneira de ilustrar a comunidade estratégica com o uso do conceito do ba, pode ser o proposto na Figura 9, onde os diversos bas levam os participantes a terem pontos de vista internos e externos, e ao mesmo tempo fornece um contexto compartilhado em movimento onde os próprios contextos estão envolvidos, similar à necessidade de ressonância das competências entre os membros da comunidade estratégica para obtenção de um objetivo comum descrita na seção 2.3. Conseqüentemente, a comunidade estratégica pode então formar o espaço e tempo fenomenológico onde o conhecimento emerge, que pode ser a plataforma de ressonância do senso de valor dentro de uma estratégia comum da comunidade ilustrada na Figura 8.

No ba os gerentes tornam-se líderes e crescem as suas capacidades para sintetizar vários bas através da sua experiência de participação no ba, que também podem 


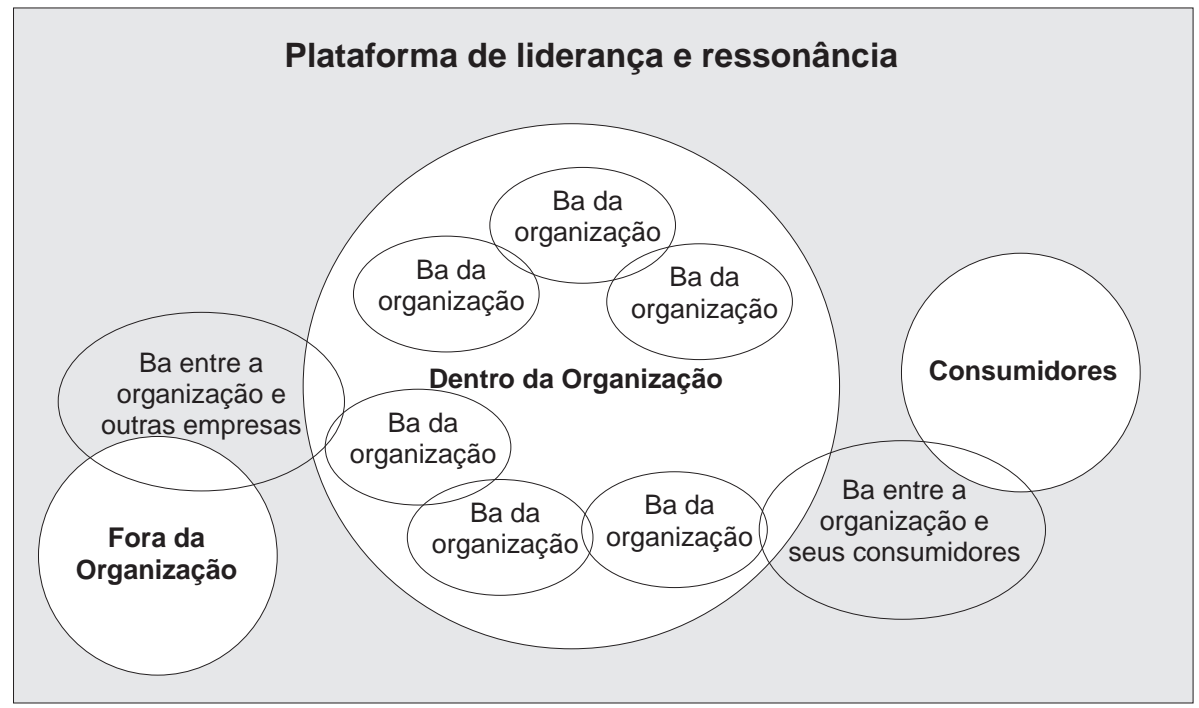

Figura 9 - Relacionamento dos bas da comunidade estratégica na plataforma de liderança e ressonância

ser os líderes da comunidade ilustrado na Figura 9.

Desta maneira, o conceito do ba funde a plataforma de ressonância e a liderança inovadora na plataforma de liderança e ressonância, conforme ilustrado na Figura 8.

\subsection{Quanto à interação das ferramentas da TI com as fases do processo de espiralar}

Na rede da comunidade se usam prioritariamente ferramentas multimídias, pois proporcionam interatividade, fácil comunicação, debate e decisão. No entanto, não há como realizar a interatividade prescindindo das demais ferramentas de organização, armazenamento e busca do conhecimento adquirido. Na prática as ferramentas de multimídia também são apoiadas pelas demais ferramentas, que também podem ser acessadas através das ferramentas multimídias. Desta maneira, na representação das ferramentas da TI no quadro da Figura 4 precisam ser adicionadas as ferramentas multimídias da rede da comunidade se relacionando com as demais ferramen- tas, conforme ilustrado na Figura 10, onde o espiralar do conhecimento interage continuamente através das ferramentas multimídias da rede da comunidade em relação direta com as demais ferramentas de apoio de cada quadrante do processo SECI.

\subsection{Quanto à proposta de umframework mais completo}

O processo de inovação no conhecimento da comunidade estratégica através do espiralar, junto com a ligação interativa com o avanço das competências da comunidade, pode ser entendido de acordo com o processo SECI descrito na seção 2.2.

Neste processo ocorre o avanço das competências quando o conhecimento explícito dos elementos da comunidade é compartilhado e internalizado, utilizando-o para ampliar, estender e reformular seus próprios conhecimentos tácitos. Os modos de compartilhamento,

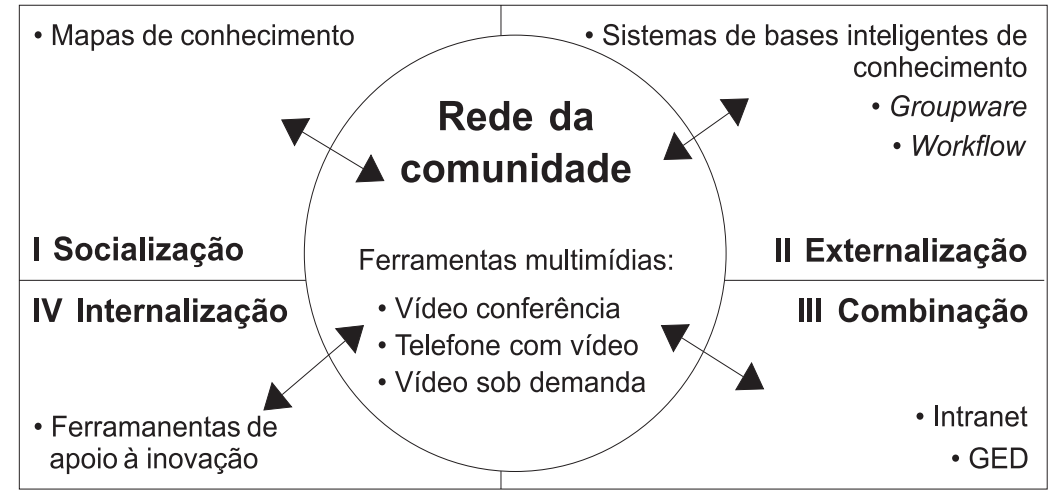

Figura 10 - Relacionamento entre as ferramentas da TI da rede da comunidade e demais ferramentas 


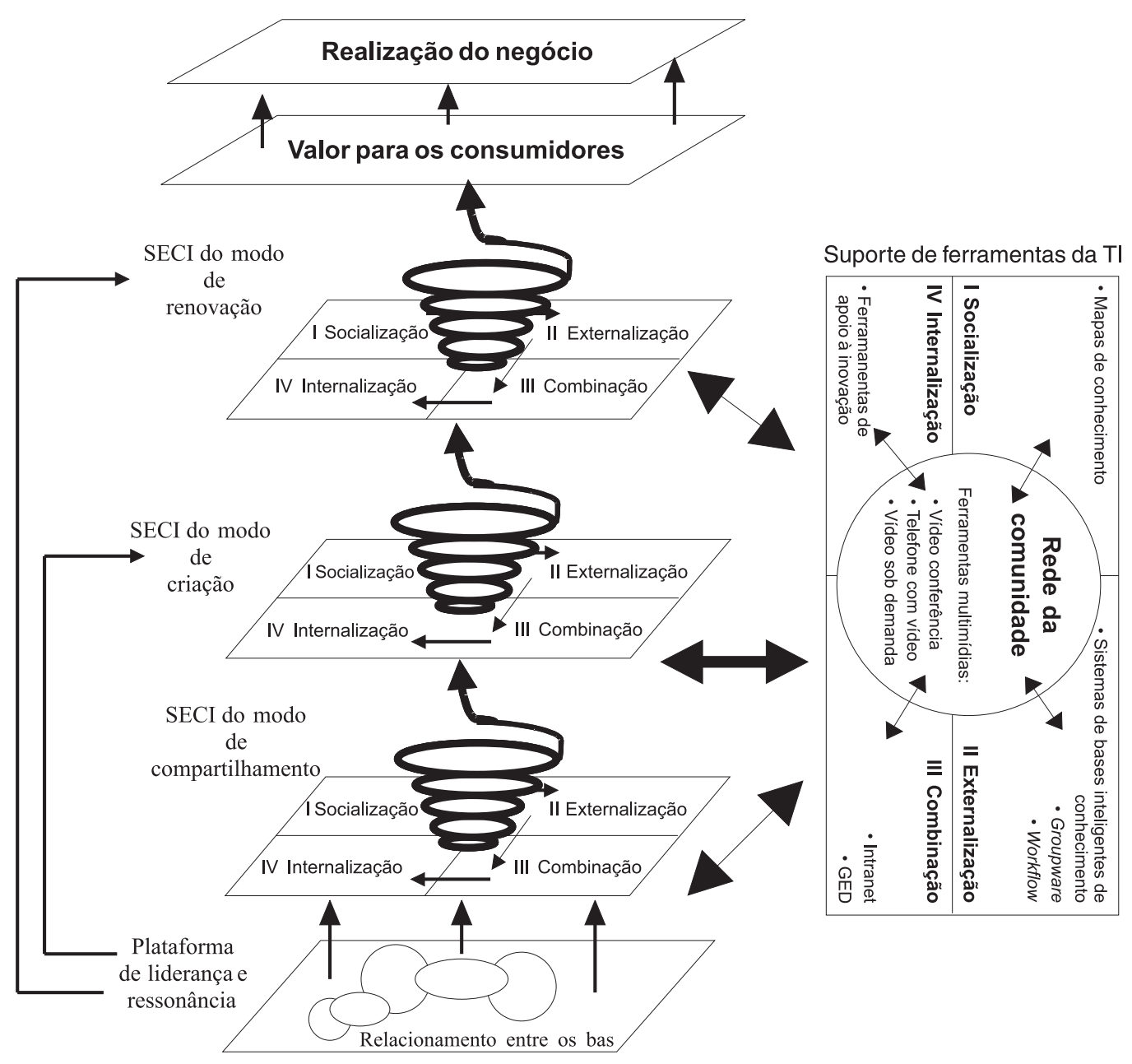

Figura 11 - Dinâmica da comunidade estratégica

criação e renovação da comunidade estratégica descritos na seção 2.3 podem ser associados às diferentes espirais que são disparadas conforme o conhecimento da espiral anterior torna-se amplo e move-se para níveis ontológicos. O espiralar em um sentido pode provocar o avanço da competência da comunidade, ao mesmo tempo em que no sentido inverso se aproveita do conhecimento adquirido para continuar o seu movimento espiral, ou seja, interagem continuamente. As novas espirais podem se expandir horizontalmente e verticalmente de acordo como ela se move pelos bas da comunidade. Esse mecanismo pode ser ilustrado conforme a Figura 11, a qual sintetiza a dinâmica da criação e disseminação do conhecimento da comunidade estratégica, incluindo as explorações realizadas neste artigo.

\section{Conclusões}

\subsection{Resultados mais importantes}

A comunidade estratégica pode ser representada por bas conectados que fundem sob o mesmo conceito o embasamento proporcionado pelos líderes e a plataforma de ressonância do senso de valor de uma estratégia comum da comunidade.

As ferramentas da TI dividem-se entre aquelas que proporcionam a interação e as que apóiam para que esta interação possa acontecer. A rede da comunidade é utilizada em todo processo de criação do conhecimento, enquanto que as demais ferramentas são apropriadas para certos quadrantes do processo. A interação ocorre através das ferramentas multimídias da rede da comunidade, mas dependem também das demais ferramentas, as quais podem ser acessadas diretamente, ou através das ferramentas da comunidade.

O avanço das competências resulta do espiralar do conhecimento até níveis ontológicos, quando ocorre o disparo de uma nova espiral. Os modos de avanço das competências podem ser associados a cada espiral.

Ao utilizar a conceituação do ba em conjunto com o processo de espiralar o conhecimento e com a interação das ferramentas da TI, consegue-se apresentar um modelo mais completo da dinâmica de funciona- 
mento da comunidade estratégica.

\subsection{Principais contribuições}

Há avanço com o esclarecimento do local onde é criado o conhecimento através do uso do conceito do ba, ou seja, como são as interações na plataforma de ressonância da comunidade estratégica.

Esclarece o uso das ferramentas da TI nas fases apropriadas do espiralar do conhecimento.

Agrega às contribuições de Kadama (2002) e Kodama (1999a; 1999b; 1999c; 2002) as explorações deste artigo em um único framework.

\subsection{Restrições e/ou limitações}

A principal restrição e/ou limitação é referente à dinâmica do conceito do ba, que ainda parece se tratar de um conceito de caráter filosófico, pois não se encontra uma modelagem explícita. Assim sendo, como agenda de trabalhos futuros devem ser buscados mecanismos empíricos que comprovem a sua dinâmica.

\section{Referências}

BLACKLER, F. Knowledge, knowledge work and organizations: an overview and interpretation. Organization Studies (sine loco), v. 6, n. 16, p. 10211046, 1995.

BRESNEN, M. et al. Social practices and the management of knowledge in project enviroments. International Journal of Project Management, v. 21, n. 3 , p. 157-66, 2003.

CARVALHO, R. B.; FERREIRA, M. A. T. Acelerando a espiral do conhecimento com a tecnologia da informação. In: International symposium on knowledge management / document management, ISKM/DM 2001, 4., 2001, Curitiba. Anais. Curitiba: PUC-PR, 2001. v. 1. p. 109-125.

DONK, D. P.; RIEZEBOS, J. Exploring the knowledge inventory in project-based organizations: a case study. International Journal of Project Management, 2004. www.sciencedirect.com. Acesso em: 29 nov. 2004.

DRUCKER, P. The coming of the new organization. Harvard Business Review (sine loco), p. 45-53, jan./feb. 1988.

DRUCKER, P. Post-Capitalist Society. Oxford: Butterworth-Heinemann, 1993.
DUHAN et al. Information systems strategies in knowledge-based SMEs: the role of core competences. European Journal of Information Systems (sine loco), n. 10, p. 25-40, 2001.

GIDDENS, A. The Constitution of Society. Berkeley: University of California Press, 1984.

HESSELBEIN, F. et al. The community of the future. California: Jossey-Bass, 1998.

KADAMA, M. Creating new businesses through a strategic innovation community - case study of a new interactive video service in Japan. International Journal of Project Management (sine loco), n. 20, p. 289-302, 2002.

KODAMA, M. Community management support through community-based information networks. Information Management \& Computer Security (sine loco), v. 7, n. 3, p. 140-150, 1999a.

Strategic business applications and new virtual knowledge-based businesses through community-based information networks. Information Management \& Computer Security (sine loco), v. 7 , n. 4, p. 186-199, 1999 b.

Customer value creation through communitybased information networks. International Journal of Information Management (sine loco), n. 19, p. 495508, 1999c.

Transforming an old economy company through strategic communities. Long Range Planning (sine loco), n. 35, p. 349-365, 2002.

LAWLER, E. E. From job-based to competency-based organizations. Journal of Organizational Behavior (sine loco), n. 15, p. 3-15, 1994.

LINDGREN, R.; STENMARK, D.; LJUNGBERG, J. Rethinking competence systems for knowlwdge-based organizations. European Journal of Information Systems (sine loco), n. 12, p. 18-29, 2003.

NISHIDA, K. An Inquiry into the Good. New Haven: Yale University Press, 1921 (impressão 1990).

NISHIDA, K. Fundamental Problems of Philosophy: The World of Action the Dialectical World. Tokyo: Sophia University, 1970.

NONAKA, I. A dynamic theory of organizational knowledge creation. Organization Science (sine loco), n. 5, p. 14-37, 1994. 
34 Produto \& Produção, vol. 8, n. 3, p. 21-34, out. 2005

NONAKA, I.; TAKEUCHI, H. Criação de conhecimento na empresa. Rio de Janeiro: Campus, 1997. 380 p.

NONAKA, I.; TOYAMA, R. The knowledge-creating theory revisited: knowledge creation as a synthesizing process. Knowledge Management Research \& Pratice (sine loco), n. 1, p. 2-10, 2003.

PRAHALAD, C. K.; HAMEL, G. The core competence of the corporation. Harvard Business Review (sine loco), p. 79-91, may/june 1990. 